\title{
Prevalence and correlates of alcohol and other substance use disorders in young adulthood: A population-based study
} Antti Latvala*1,2, Annamari Tuulio-Henriksson1,2, Jonna Perälä1, Samuli I Saarni ${ }^{1}$, Terhi Aalto-Setälä ${ }^{1,3}$, Hillevi Aro ${ }^{1}$, Tellervo Korhonen ${ }^{1,4}$, Seppo Koskinen ${ }^{5}$, Jouko Lönnqvist ${ }^{1,6}$, Jaakko Kaprio ${ }^{1,4,7}$ and Jaana Suvisaari ${ }^{1,8}$

Address: ${ }^{1}$ Department of Mental Health and Substance Abuse Services, National Institute for Health and Welfare, Mannerheimintie 166, FIN00300, Helsinki, Finland, ${ }^{2}$ Department of Psychology, University of Helsinki, Finland, ${ }^{3}$ Department of Child Psychiatry, Hospital for Children and Adolescents, Helsinki University Central Hospital, Finland, ${ }^{4}$ Department of Public Health, University of Helsinki, Finland, ${ }^{5}$ Welfare and Health Policies Division, National Institute for Health and Welfare, Helsinki, Finland, 'epartment of Psychiatry, University of Helsinki, Finland, ${ }^{7}$ Institute for Molecular Medicine Finland FIMM, Helsinki, Finland and ${ }^{8}$ Department of Social Psychiatry, Tampere School of Public Health, University of Tampere, Finland

Email: Antti Latvala* - antti.latvala@thl.fi; Annamari Tuulio-Henriksson - annamari.tuulio-henriksson@thl.fi; Jonna Perälä - jonna.perala@thl.fi; Samuli I Saarni - samuli.saarni@helsinki.fi; Terhi Aalto-Setälä - terhi.aalto-setala@hus.fi; Hillevi Aro - hillevi.aro@thl.fi; Tellervo Korhonen - tellervo.korhonen@helsinki.fi; Seppo Koskinen - seppo.koskinen@thl.fi; Jouko Lönnqvist - jouko.lonnqvist@thl.fi; Jaakko Kaprio - jaakko.kaprio@helsinki.fi; Jaana Suvisaari - jaana.suvisaari@thl.fi

* Corresponding author

Published: 19 November 2009

BMC Psychiatry 2009, 9:73 doi:10.1 186/147/-244X-9-73
Received: 7 May 2009

Accepted: 19 November 2009

This article is available from: http://www.biomedcentral.com/I47I-244X/9/73

(C) 2009 Latvala et al; licensee BioMed Central Ltd.

This is an Open Access article distributed under the terms of the Creative Commons Attribution License (http://creativecommons.org/licenses/by/2.0), which permits unrestricted use, distribution, and reproduction in any medium, provided the original work is properly cited.

\begin{abstract}
Background: Several risk factors for alcohol and other substance use disorders (SUDs) have been identified, but it is not well understood whether their associations with SUD are independent of each other. In particular, it is not well known, whether the associations between behavioral and affective factors and SUDs are independent of other risk factors. The incidence of SUDs peaks by young adulthood making epidemiological studies of SUDs in young adults informative.
\end{abstract}

Methods: In a comprehensive population-based survey of mental health in Finnish young adults (aged 2I-35 years, $n=605$ ), structured clinical interview (SCID-I) complemented by medical record data from all lifetime hospital and outpatient treatments were used to diagnose SUDs. We estimated the prevalences of lifetime DSM-IV SUDs, and investigated their associations with correlates from four domains representing: (I) behavioral and affective factors, (2) parental factors, (3) early initiation of substance use, and (4) educational factors. Independence of the association of behavioral and affective factors with SUD was investigated.

Results: Lifetime prevalences of abuse or dependence of any substance, alcohol, and any illicit substance were $14.2 \%, 13.1 \%$, and $4.4 \%$, respectively. Correlates from all four domains were associated with SUD. The associations between behavioral and affective factors (attention or behavior problems at school, aggression, anxiousness) and SUD were largely independent of other correlates, whereas only daily smoking and low education associated with SUD after adjustment for behavioral and affective factors. 


\begin{abstract}
Conclusion: Alcohol use disorders are common in Finnish young adults, whereas other SUDs are less common than in many other developed countries. Our cross-sectional analyses suggested that the association between behavioral and affective factors and SUD was only partly accounted for by other correlates, such as early initiation of substance use and parental alcohol problems. In contrast, associations between many other factors and SUD were non-significant when adjusted for behavioral and affective factors.
\end{abstract}

\section{Background}

Substance use disorders (SUDs) are among the most common psychiatric disorders and constitute a major public health concern. Recent epidemiological surveys have reported lifetime prevalences of DSM-IV any substance abuse or dependence between $10-20 \%$ in the general population $[1,2]$. Several factors, occurring at the level of individual, interpersonal relations, or society, have been found to increase the risk for SUDs.

A behavioral-temperamental trait often termed disinhibition has been widely recognized as an important risk factor for alcohol and other substance use disorders [3-12]. This trait is characterized by difficulty of inhibiting behavioral impulses, resulting in aggressive or otherwise problematic behavior. Aggression, a key feature in a subtype of conduct disorder and in antisocial personality disorder, is affected by both genetic and environmental factors $[13,14]$. Childhood aggression predicts substance use problems in adulthood [15], and alcohol abusers often show elevated trait aggressiveness [16].

Besides disinhibitory behavior, also affective traits such as anxiousness may increase the risk for problematic substance use [17]. Mood and anxiety disorders are frequently comorbid with SUDs $[18,19]$, often preceding them, but the processes underlying these associations are not well known [20].

One of the strongest indicators of risk for SUDs is a family history of SUDs. Familial transmission of, and genetic contribution to SUDs are well established $[21,22]$. Parental SUD also predicts earlier onset of substance dependence in the offspring [23].

The heightened risk related to early onset of substance use is also well established [24]. In addition to being a causal factor, early onset of use may be a marker of pre-existing liability to SUD [25]. Early initiation and heavy smoking have also been found to be risk factors for heavy drinking, and alcohol and other substance use disorders $[27,28]$.

In epidemiological studies, low educational level has consistently been found to associate with SUDs [2,3,11]. Low educational attainment and school problems in adolescence predict substance use and disorders in young adult- hood [29]. In addition to own education, parental low education may be related to heavy substance use [30].

Risk factors for SUD are often found to co-occur. For example, parental SUD is associated with behavioral and affective problems in the offspring [31-33], probably accounted for by both genetic and non-genetic familial effects. In addition, both familial alcoholism and disinhibitory traits have been found to predict earlier initiation of use of various substances [23,31,34]. All in all, the the relative importance of different risk factors for SUD and their independence of each other's effects are not well understood.

In the present study, variables representing the four domains of (1) behavioral and affective factors, (2) parental factors, (3) early initiation of substance use, and (4) educational factors were studied as correlates of alcohol and other substance use disorders in young adulthood. As substance use and the incidence of SUDs generally peak around this age [2,35], studying young adults captures most cases within a reasonably short period after disorder onset and minimizes complications arising from the course of the disorder. Using data from a survey representative of the Finnish population, and comprehensive diagnostic assessment, our first aim was to estimate the prevalence of alcohol and other substance use disorders among Finnish young adults. Secondly, we aimed to investigate the relative importance of behavioral and affective factors, parental factors, early initiation of substance use, and educational factors as correlates of SUD, specifically focusing on whether behavioral and affective factors and correlates from other domains associate with SUD independently of each other. Based on previous research, we expected correlates from all the selected domains to individually associate with SUD. Further, we hypothesized that behavioral and affective factors would show strong associations with SUD even when other domains are taken into account, but that associations between many other factors and SUD would be diminished controlling for behavioral and affective factors.

\section{Methods \\ Sample}

The data reported here come from a population-based sample of Finnish young adults. The sample was initially 
assessed in 2001 as part of the nationwide Health 2000 Survey [19,36,37] and re-examined in 2003-2005 to investigate psychiatric disorders among young adults in the Mental Health in Early Adulthood in Finland (MEAF) study [38,39] (Figure 1). MEAF was a two-phase study. In the first phase, a questionnaire was sent to all living members of the original study population who had not refused further contact. In the second phase, persons who were screened positive for mental health or substance use problems, and a random sample of screen-negative persons were invited to a mental health interview.
The MEAF questionnaire included several scales assessing mental health and substance use, to be used as screens for the mental health interview. Two separate screens were used to assess substance use: score of at least three in the CAGE questionnaire [40] for alcohol use, and selfreported use of any illicit drug at least six times. In addition to screen-positive persons, individuals with hospital treatment due to any mental or substance use disorder (ICD Chapter V: Mental and behavioural disorders) during the lifetime according to the Finnish Hospital Discharge Register information were asked to participate in the interview.

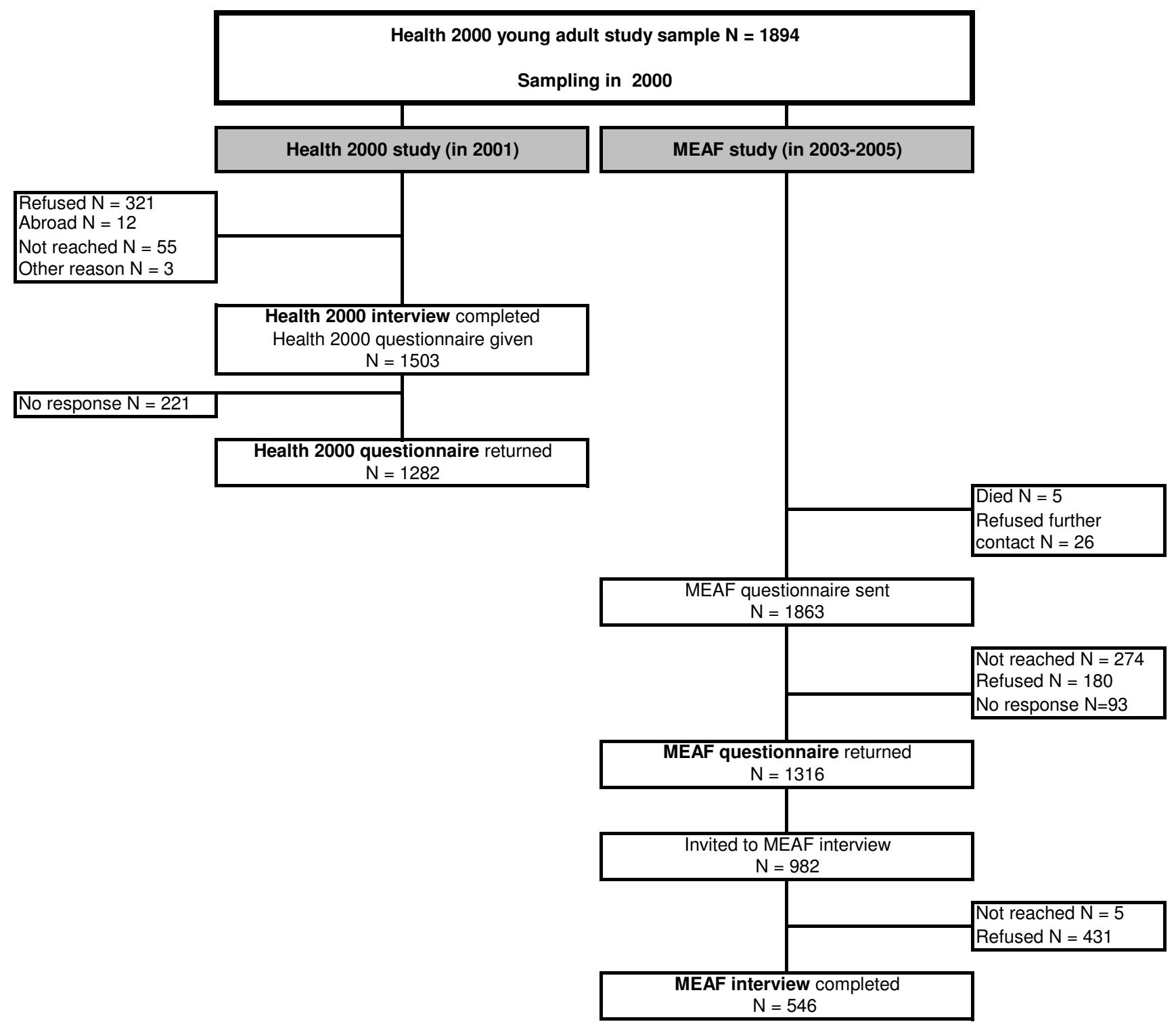

Figure I

Sampling and data collection in the Health 2000 and Mental Health in Early Adulthood in Finland (MEAF) studies. 
Because of the study design, there were non-respondents in two study phases: in the questionnaire containing the screens for the interview, and in the interview. Of the 1863 members of the original study population approached, $1316(70.6 \%)$ returned the questionnaire. Participation in the interview was $55.8 \%$ (458/821) for the screen-positive and $54.7 \%$ (88/161) for the invited screen-negative persons. Previous analyses indicated that attrition in both study phases was related to age, sex, and education, but not to self-reported mental health disorders or symptoms, including the CAGE scores [38]. Age, sex, and attained education in 2001 were used when calibrating post-stratification weights to correct for nonresponse.

The study protocol was accepted by the ethics committees of the National Public Health Institute and the Hospital District of Helsinki and Uusimaa. Participants provided written informed consent.

\section{Alcohol and other substance use disorder diagnoses}

The mental health interview was the Research Version of Structured Clinical Interview for DSM-IV-TR [41]. All interviews were conducted by experienced research nurses or psychologists, and were reviewed by the interviewer together with a psychiatrist. For the final diagnostic assessment all case notes from hospital and outpatient treatments were obtained, excluding individuals who had refused any participation in the Health 2000 study. The final best-estimate diagnoses were made by two psychiatrists and two residents in psychiatry. Diagnostic evaluation was based on all available information from the interview and/or case records. All SUDs except for nicotine dependence were assessed.

Diagnostic assessment was completed in 605 individuals (aged 21-35 years), of whom 546 participated in the psychiatric interview and the rest were diagnosed based on case records. The reliability of the diagnoses was tested on 40 cases rated by all four clinicians. For alcohol abuse or dependence, the unweighted kappa values between each pair of raters ranged from 0.94 to 1.00. A detailed description of the methods of MEAF has been provided elsewhere
[38]. The present investigation utilized data from both Health 2000 and MEAF studies (Figure 1, Table 1).

\section{Behavioral and affective factors}

Attention or behavior problems at school

A set of questions concerning difficulties during school time, lasting longer than one semester (four to five months), was asked. A positive response to either of the items on attention or behavior problems indicated attention or behavior problems at school.

\section{Aggression}

A short measure of trait aggressiveness was constructed based on selected items from the Buss-Perry Aggression Questionnaire [42]. Two items from each of the four aggression subscales were translated into Finnish, creating an eight-item scale. A summary scale of the eight items, responded to on a five-point Likert scale, was constructed (theoretical range 8-40, Cronbach's alpha $=.82$ ). Aggression scores were further classified as low $(<11)$, moderate (11-17), and high (>17), approximating the observed $25^{\text {th }}$ and $75^{\text {th }}$ percentiles.

\section{Anxiousness}

Trait anxiousness was measured with a single item, which has been used as a measure of anxiousness in previous studies in Finland [43]. The question asked was "Are you usually tense or distressed?". The five-point scale was: 1 "I have good control over my feelings and do not become tense or distressed easily", 2 "I do not feel tense or distressed", 3 "I become distressed quite easily", 4 "I become anxious, tense or distressed very easily", and 5 "I feel anxious or tense all the time as if I had lost my nerves". A three-class variable was created by classifying anxiousness scores 1 and 2 as low, score 3 as moderate, and scores 4 and 5 as high.

\section{Parental factors}

\section{Parental alcohol problems}

A series of questions concerning various childhood adversities, experienced before age 16, was asked. Items "Did your father have alcohol problems" and "Did your mother have alcohol problems" were combined so that a

Table I: Variables used in logistic regression models, and their origins in different study phases.

\begin{tabular}{|c|c|}
\hline Study phase & Variables \\
\hline \multicolumn{2}{|l|}{ Health 2000* } \\
\hline Questionnaire & Parental alcohol problems \\
\hline Interview & Attention or behavior problems at school, Parental basic education, Learning difficulties at school \\
\hline \multicolumn{2}{|r|}{${ }^{x}$} \\
\hline Questionnaire & Aggression, Anxiousness, Age at initiation of daily smoking, Age at initiation of drinking to intoxication \\
\hline Interview & SUD diagnoses, Basic education \\
\hline
\end{tabular}

MEAF, Mental Health in Early Adulthood in Finland

$*$ in 2001

** in 2003-2005 
positive response to either item was considered as an indicator of parental alcohol problems.

\section{Parental basic education}

Using the highest secondary educational level of both parents, parental basic education was classified as a binary variable of having at least some high school studies or less than high school.

\section{Substance use initiation}

\section{Age at initiation of daily smoking}

Lifetime never-smokers formed their own category, while for smokers the age at daily smoking initiation was classified into three classes: 18 years or older, 15-17 years, and younger than 15 years.

\section{Age at initiation of drinking to intoxication}

The question "At which age were you for the first time so drunk that you felt sick afterwards?" was asked. Three classes were created for the age at initiation of drinking to intoxication: those responding "Never" or at age 18 or older, at age 15-17, and at age younger than 15 years.

\section{Educational factors}

Learning difficulties at school

Having had learning difficulties at school was determined as a positive response to any of the four learning related difficulties items (Reading, Writing, Mathematics, Languages) in the set of questions related to school time problems. The variable for learning difficulties at school thus represents learning difficulties in reading, writing, mathematics, or languages (or any combination of these) lasting longer than one semester in elementary school.

\section{Basic education}

A binary variable for basic education was created coding high school degree and less than high school as separate categories.

\section{Statistical analysis}

The lifetime prevalences of substance-specific abuse and dependence diagnoses and any substance abuse or dependence were estimated separately for men and women. Next, the associations between the selected risk factors and lifetime any substance abuse or dependence were studied, first using t-tests and chi-square tests, and then with a series of logistic regression models. These logistic regression models were designed to provide information on whether behavioral and affective factors and risk factors from other domains associate with SUD independent of each other.

The initial cluster sampling design of the Health 2000 Survey [36] was taken into account in the analyses, and post- stratification weights calibrated by Statistics Finland were used to adjust for non-response. These weights correct the survey distributions to correspond to the population distributions. In addition, the two-phase screening for the MEAF mental health interview was taken into account using expansion weights calculated for the screen-positives $(\mathrm{M})$ by dividing their total by the number interviewed (M1), i.e. $M / M 1$, and for the screen-negatives in the same way, N/N1 $[44,45]$. These weights were calculated separately for men and women. The final weights used in statistical analyses were obtained by multiplying the expansion weights by the post-stratification weights. The weighting procedure has been described in more detail elsewhere [38]. The statistical analyses were performed using Stata 9 with survey settings [46].

\section{Missing data}

Data from four distinct sources were utilized in the logistic regression models (Table 1, Figure 1). Of the 546 individuals who participated in the MEAF interview, six were dropped because of missing information in three variables from the MEAF questionnaire (Aggression, Anxiousness, and Age at initiation of drinking to intoxication). In addition, there were five individuals who had responded to seven out of the eight items of the aggression scale in the MEAF questionnaire. For these individuals the mean of the seven existing responses for each individual was substituted for the missing value. Further, in order to use all available information, individuals who had participated in the MEAF interview but had missing data in any of the four variables from the Health 2000 study (Table 1) were also included in the logistic regression analyses by coding missingness as a separate category of these categorical variables [47].

\section{Results \\ Lifetime prevalence of alcohol and other substance use disorders}

The lifetime prevalence of any substance abuse or dependence was $14.2 \%$ (95\% CI: 11.6-17.4\%). In general, prevalences were higher in men than in women (for any substance abuse or dependence $20.9 \%$ [95\% CI: 16.5 $26.1 \%$ ] vs. $7.4 \%$ [95\% CI: 4.9-10.9\%], respectively). Alcohol diagnoses were decidedly most prevalent (13.1\%), followed by cannabis $(1.7 \%)$ and amphetamine $(1.5 \%)$. The prevalence of opioid dependence was $1.0 \%$, and that of any illicit drug abuse/dependence $4.4 \%$ (Table 2). Of the cases with SUD diagnosis, $24 \%$ had an abuse or dependence diagnosis in two or more classes of substances. The prevalence of any illicit substance diagnosis without comorbid alcohol diagnosis was $1.1 \%$. In $53 \%$ of the cases with SUD the age at onset of abuse/dependence was 18 years or younger. 
Table 2: Prevalences and $95 \%$ confidence intervals $(\mathrm{Cl})$ of lifetime substance use disorders among young adults in Finland $(\mathrm{n}=605)^{\mathrm{a}}$

\begin{tabular}{|c|c|c|c|c|c|c|}
\hline & \multicolumn{2}{|c|}{ Males } & \multicolumn{2}{|l|}{ Females } & \multicolumn{2}{|c|}{ Total } \\
\hline & $\%$ & $(95 \% \mathrm{CI})$ & $\%$ & $(95 \% \mathrm{CI})$ & $\%$ & $(95 \% \mathrm{Cl})$ \\
\hline Any substance* abuse/dependence & 20.9 & $(16.5-26.1)$ & 7.4 & $(4.9-10.9)$ & 14.2 & $(11.6-17.4)$ \\
\hline Alcohol abuse/dependence & 19.8 & $(15.6-24.8)$ & 6.3 & $(4.1-9.6)$ & 13.1 & $(10.5-16.2)$ \\
\hline Abuse & 11.6 & $(8.4-15.6)$ & 3.4 & $(1.8-6.2)$ & 7.6 & $(5.7-10.0)$ \\
\hline Dependence & 8.2 & $(5.7-11.7)$ & 2.9 & $(1.6-5.3)$ & 5.6 & $(4.0-7.7)$ \\
\hline Cannabis abuse/dependence & 2.7 & $(1.4-5.3)$ & 0.7 & $(0.2-2.4)$ & 1.7 & $(1.0-3.1)$ \\
\hline Abuse & 1.4 & $(0.6-3.5)$ & 0.6 & $(0.1-2.3)$ & 1.0 & $(0.5-2.1)$ \\
\hline Dependence & 1.3 & $(0.5-3.4)$ & 0.2 & $(0.0-1.2)$ & 0.7 & $(0.3-1.8)$ \\
\hline Amphetamine abuse/dependence & 1.9 & $(0.9-4.0)$ & 1.0 & $(0.3-3.1)$ & 1.5 & $(0.8-2.7)$ \\
\hline Abuse & 0.2 & $(0.0-1.5)$ & 0 & & 0.1 & $(0.0-0.8)$ \\
\hline Dependence & 1.7 & $(0.7-3.8)$ & 1.0 & $(0.3-3.1)$ & 1.3 & $(0.7-2.6)$ \\
\hline Opioid abuse/dependence & 1.3 & $(0.5-3.4)$ & 0.7 & $(0.2-2.7)$ & 1.0 & $(0.4-2.2)$ \\
\hline Abuse & 0 & & 0 & & 0 & \\
\hline Dependence & 1.3 & $(0.5-3.4)$ & 0.7 & $(0.2-2.7)$ & 1.0 & $(0.4-2.2)$ \\
\hline Sedative abuse/dependence & 1.6 & $(0.7-3.9)$ & 0 & & 0.8 & $(0.3-2.0)$ \\
\hline Abuse & 0.7 & $(0.2-2.6)$ & 0 & & 0.3 & $(0.1-1.4)$ \\
\hline Dependence & 0.9 & $(0.3-2.9)$ & 0 & & 0.5 & $(0.2-1.5)$ \\
\hline Other substance abuse/dependence & 1.6 & $(0.7-3.6)$ & 0 & & 0.8 & $(0.4-1.8)$ \\
\hline Polysubstance dependence & 1.1 & $(0.4-3.1)$ & 0.9 & $(0.3-2.8)$ & 1.0 & $(0.5-2.2)$ \\
\hline Drug abuse/dependence & 6.8 & $(4.4-10.2)$ & 2.0 & $(0.9-4.2)$ & 4.4 & $(3.1-6.3)$ \\
\hline
\end{tabular}

a Calculated using expansion weights

* Excluding tobacco

\section{Correlates}

\section{Unadjusted associations}

Distributions of age, gender, and correlates from the four domains in people with and without SUD are presented in Table 3. On average, individuals with a SUD diagnosis were older than individuals with no SUD diagnosis $[\mathrm{t}(538)=-2.9, \mathrm{p}<.01]$, and the male:female ratio was higher in the diagnosis group $\left[\chi^{2}(1)=27.9, \mathrm{p}<.001\right]$. Individually, all variables from the four domains were significantly associated with SUD (Table 3 ).

Interactions between gender and all correlates were also assessed, and significant interactions between gender and aggression, and gender and parental education $(\mathrm{p}<.01$ in both cases) were observed. All women with SUD scored moderate or high in aggression, whereas one fifth of men with SUD scored low in aggression. The interaction between parental education and gender was due to there being no differences in the distribution of parental education between women with and without SUD, whereas low parental education was more common in men with SUD $\left(\chi^{2}(2)=37.6, \mathrm{p}<.001\right)$.

\section{Adjusted associations}

Next, a series of logistic regression models was conducted to assess the associations between behavioral and affective factors and SUD adjusting for correlates from other domains. To facilitate interpretation of the models, the unadjusted associations from Table 3 are presented as odds ratios (ORs) in the first column of Table 4 . The sec- ond column gives the adjusted odds ratios (AORs) for each variable adjusting for the other variables in the same domain, and the third column further adjusts these associations for age and gender.

In Model I, behavioral and affective factors and the covariates age and gender were included as predictor variables. When assessed simultaneously, all three variables (attention or behavior problems at school, aggression, and anxiousness) still had significant associations with SUD diagnosis (AORs 2.2-6.8) (Table 4).

Model I established the baseline for the effect of behavioral and affective factors, with which the subsequent models could be compared. In Model II (Table 4), parental factors were added. The AORs of attention or behavior problems at school and aggression remained significant and the changes in odds ratios were not significant. The effect of high anxiousness almost attained statistical significance $(\mathrm{p}=.053)$. Among parental factors only missing information for parental alcohol problems associated with SUD. In Model III (Table 4), the effect of early initiation of substance use was assessed. Age at initiation of drinking to intoxication was not associated with risk for SUD, whereas daily smoking was associated with elevated risk. Initiation of daily smoking before age 15 showed a large effect $(A O R=8.5)$. Behavioral and affective measures remained significant predictors of SUD, but the AOR of attention or behavior problems at school was reduced compared to Model I (adjusted Wald test, $\mathrm{p}=.042$ ). In 
Table 3: Differences in covariates and risk factors from four domains between individuals with and without SUD diagnosis $(n=540)$

\begin{tabular}{|c|c|c|c|c|}
\hline & No SUD diagnosis $(n=464)$ & SUD diagnosis $(n=76)$ & t or $\chi^{2}(d f)$ & $\mathbf{P}$ \\
\hline \multicolumn{5}{|l|}{ Covariates } \\
\hline Age: Mean (SD) & $27.9(3.6)$ & $29.2(3.7)$ & $-2.88(538)$ & $<.01$ \\
\hline \multicolumn{5}{|l|}{ Gender, \% } \\
\hline Female & 62.5 & 30.3 & & \\
\hline Male & 37.5 & 69.7 & $27.85(\mathrm{I})$ & $<.001$ \\
\hline \multicolumn{5}{|c|}{ Behavioral \& affective factors } \\
\hline \multicolumn{5}{|c|}{ Attention or behavior problems at school, \% } \\
\hline No & 87.1 & 43.4 & & \\
\hline Yes & 7.1 & 32.9 & & \\
\hline Missing & 5.8 & 23.7 & $80.82(2)$ & $<.001$ \\
\hline \multicolumn{5}{|l|}{ Aggression, \% } \\
\hline Low & 21.6 & 13.2 & & \\
\hline Moderate & 59.7 & 36.8 & & \\
\hline High & 18.8 & 50.0 & $35.85(2)$ & $<.001$ \\
\hline \multicolumn{5}{|l|}{ Anxiousness, \% } \\
\hline Low & 77.2 & 59.2 & & \\
\hline Moderate & 19.6 & 26.3 & & \\
\hline High & 3.2 & 14.5 & $21.38(2)$ & $<.001$ \\
\hline \multicolumn{5}{|l|}{ Parental factors } \\
\hline \multicolumn{5}{|c|}{ Parental alcohol problems, \% } \\
\hline No & 66.4 & 31.6 & & \\
\hline Yes & 21.8 & 26.3 & & \\
\hline Missing & 11.9 & 42.1 & $50.56(2)$ & $<.001$ \\
\hline \multicolumn{5}{|l|}{ Parental basic education, $\%$} \\
\hline Some high school & 30.4 & 13.2 & & \\
\hline Less than high school & 61.4 & 60.5 & & \\
\hline Missing & 8.2 & 26.3 & $23.92(2)$ & $<.001$ \\
\hline \multicolumn{5}{|c|}{ Age at substance use initiation } \\
\hline \multicolumn{5}{|c|}{ Smoking, \% } \\
\hline Non-smoker & 47.8 & 13.2 & & \\
\hline$>17$ years & 14.7 & 18.4 & & \\
\hline $15-17$ years & 24.8 & 32.9 & & \\
\hline$<15$ years & 12.7 & 35.5 & $41.89(3)$ & $<.001$ \\
\hline \multicolumn{5}{|l|}{ Drinking to intoxication, $\%$} \\
\hline$>17$ years or never & 32.5 & 15.8 & & \\
\hline $15-17$ years & 48.5 & 44.7 & & \\
\hline$<15$ years & 19.0 & 39.5 & $18.83(2)$ & $<.001$ \\
\hline \multicolumn{5}{|c|}{ Learning \& education } \\
\hline \multicolumn{5}{|c|}{ Learning difficulties at school, \% } \\
\hline No & 86.4 & 56.6 & & \\
\hline Yes & 7.8 & 19.7 & & \\
\hline Missing & 5.8 & 23.7 & $42.00(2)$ & $<.001$ \\
\hline \multicolumn{5}{|l|}{ Basic education, $\%$} \\
\hline High school & 61.6 & 23.7 & & \\
\hline Less than high school & 38.4 & 76.3 & $38.23(1)$ & $<.001$ \\
\hline
\end{tabular}

SUD, substance use disorder; SD, standard deviation

Model IV (Table 4), a similar analysis was conducted with measures of learning and education. Learning difficulties at school showed no risk independent of behavioral and affective factors, but not having a high school degree was associated with SUD (AOR = 3.1). Attention or behavior problems at school, high aggression, and anxiousness still had significant associations with SUD, but the AOR of high aggression was reduced compared to Model I (adjusted Wald test, $\mathrm{p}=.020$ ).
Finally, in Model V (Table 4), the correlates from all four domains were assessed simultaneously. Adjusting for all the correlates, the AORs of attention or behavior problems at school and anxiousness remained significant, whereas high aggression failed to reach statistical significance $(\mathrm{p}=.065)$. Of the other domains, only age at initiation of daily smoking emerged as a statistically significant correlate. Compared to non-smokers, smokers regardless of the age at initiation were at elevated risk. Having initi- 
Table 4: Associations (odds ratios) between risk factors from four domains and lifetime any substance abuse/dependence among young adults in Finland ( $\mathrm{n}=540$ )

\begin{tabular}{|c|c|c|c|c|c|c|c|c|c|c|c|c|c|c|c|c|}
\hline & Univa & triate & Bloc & & Bloc & estage \& sex & Model I & & Model II & & Model III & & Model IV & & Model V & \\
\hline & OR & (95\% Cl) & $\begin{array}{l}\text { A } \\
\text { OR }\end{array}$ & $(95 \% \mathrm{Cl})$ & $\begin{array}{l}\text { A } \\
\text { OR }\end{array}$ & $(95 \% \mathrm{Cl})$ & AOR & $(95 \% \mathrm{Cl})$ & AOR & $(95 \% \mathrm{Cl})$ & AOR & $(95 \% \mathrm{Cl})$ & AOR & $(95 \% \mathrm{Cl})$ & AOR & $(95 \% \mathrm{Cl})$ \\
\hline $\begin{array}{l}\text { Behavioral } \\
\& \text { affective } \\
\text { factors }\end{array}$ & & & & & & & & & & & & & & & & \\
\hline $\begin{array}{l}\text { Attention or } \\
\text { behavior } \\
\text { problems at } \\
\text { school }\end{array}$ & & & & & & & & & & & & & & & & \\
\hline No & 1 & & 1 & & 1 & & 1 & & 1 & & 1 & & I & & I & \\
\hline Yes & 11.6 & $(5.61-23.97)$ & 7.0 & $(3.27-14.79)$ & 6.8 & $(2.93-15.63)$ & 6.8 & $(2.93-15.63)$ & 6.0 & $(2.53-14.19)$ & 5.0 & $(2.02-12.23)$ & 4.9 & $(1.80-13.48)$ & 3.4 & $(1.13-10.11)$ \\
\hline Missing & 11.2 & $(5.64-22.15)$ & 8.3 & $(4.21-16.55)$ & 8.1 & (4.15-15.72) & 8.1 & (4.15-15.72) & 2.2 & $(.20-24.08)$ & 5.2 & $(2.29-11.95)$ & 6.5 & $(3.25-13.11)$ & 1.6 & $(.24-11.09)$ \\
\hline Aggression & & & & & & & & & & & & & & & & \\
\hline Low & 1 & & 1 & & 1 & & 1 & & 1 & & 1 & & 1 & & 1 & \\
\hline Moderate & 1.4 & $(.61-3.34)$ & 1.3 & $(.56-2.99)$ & 1.6 & $(.67-3.87)$ & 1.6 & $(.67-3.87)$ & 1.8 & $(.74-4.17)$ & 1.4 & $(.52-3.56)$ & 1.4 & $(.55-3.37)$ & 1.3 & $(.5 I-3.4 I)$ \\
\hline High & 7.6 & $(3.59-16.03)$ & 3.5 & (1.55-7.80) & 4.3 & $(1.84-9.90)$ & 4.3 & $(1.84-9.90)$ & 4.1 & (1.77-9.64) & 3.5 & (1.32-9.44) & 3.0 & $(1.21-7.61)$ & 2.7 & $(.94-7.79)$ \\
\hline Anxiousness & & & & & & & & & & & & & & & & \\
\hline Low & 1 & & 1 & & 1 & & 1 & & 1 & & 1 & & 1 & & 1 & \\
\hline Moderate & 2.5 & $(1.39-4.54)$ & 1.4 & $(.69-2.99)$ & 2.2 & $(1.01-4.65)$ & 2.2 & $(1.01-4.65)$ & 2.0 & $(.92-4.40)$ & 2.9 & $(1.37-6.19)$ & 2.5 & $(1.14-5.40)$ & 3.0 & $(1.33-6.91)$ \\
\hline High & 7.7 & $(2.87-20.58)$ & 1.8 & $(.58-5.62)$ & 3.0 & $(.92-9.98)$ & 3.0 & $(.92-9.98)$ & 3.2 & $(.99-10.40)$ & 3.8 & $(1.08-13.65)$ & 3.2 & $(.86-\mid 1.71)$ & 4.0 & $(1.07-15.14)$ \\
\hline $\begin{array}{l}\text { Parental } \\
\text { factors }\end{array}$ & & & & & & & & & & & & & & & & \\
\hline $\begin{array}{l}\text { Parental } \\
\text { alcohol } \\
\text { problems }\end{array}$ & & & & & & & & & & & & & & & & \\
\hline No & 1 & & 1 & & 1 & & & & 1 & & & & & & 1 & \\
\hline Yes & 2.4 & $(1.22-4.76)$ & 2.2 & (1.09-4.44) & 2.4 & $(1.13-5.03)$ & & & 1.5 & $(.72-3.30)$ & & & & & 1.6 & $(.73-3.59)$ \\
\hline Missing & 6.5 & $(3.22-13.05)$ & 4.3 & $(1.75-10.77)$ & 3.6 & $(1.36-9.73)$ & & & 3.4 & (1.03-11.58) & & & & & 2.7 & $(.82-9.04)$ \\
\hline $\begin{array}{l}\text { Parental } \\
\text { basic } \\
\text { education }\end{array}$ & & & & & & & & & & & & & & & & \\
\hline $\begin{array}{l}\text { Some } \\
\text { high } \\
\text { school }\end{array}$ & 1 & & 1 & & 1 & & & & 1 & & & & & & 1 & \\
\hline $\begin{array}{l}\text { Less than } \\
\text { high } \\
\text { school }\end{array}$ & 2.9 & $(1.38-6.23)$ & 2.8 & $(1.28-5.93)$ & 3.0 & $(1.35-6.55)$ & & & 2.3 & $(.97-5.60)$ & & & & & 1.9 & $(.78-4.76)$ \\
\hline Missing & 12.3 & $(5.11-29.63)$ & 5.1 & (1.67-15.77) & 6.8 & $(2.06-22.54)$ & & & 2.8 & $(.20-39.57)$ & & & & & 2.6 & $(.38-18.43)$ \\
\hline
\end{tabular}

Age at
substance

substance

Daily

Daily
smoking 


\begin{tabular}{|c|c|c|c|c|c|c|c|c|c|c|c|c|c|}
\hline $\begin{array}{l}\text { Non- } \\
\text { smoker }\end{array}$ & 1 & & 1 & & 1 & & & 1 & & & & 1 & \\
\hline$>17$ years & 4.3 & $(1.70-11.01)$ & 4.0 & $(1.46-10.89)$ & 3.7 & $(1.36-9.94)$ & & 3.1 & $(1.07-9.00)$ & & & 3.4 & $(1.21-9.51)$ \\
\hline $\begin{array}{l}15-17 \\
\text { years }\end{array}$ & 5.0 & $(2.10-12.09)$ & 4.4 & (1.77-10.91) & 4.2 & $(1.64-10.82)$ & & 3.4 & $(1.29-9.18)$ & & & 3.0 & $(1.10-8.29)$ \\
\hline$<15$ years & 14.5 & $(5.92-35.33)$ & 8.9 & $(3.21-24.90)$ & 9.9 & $(3.37-28.80)$ & & 8.5 & $(2.89-25.11)$ & & & 7.5 & $(2.56-22.19)$ \\
\hline \multicolumn{14}{|l|}{$\begin{array}{l}\text { Drinking to } \\
\text { intoxication }\end{array}$} \\
\hline $\begin{array}{l}>17 \text { years } \\
\text { or never }\end{array}$ & 1 & & 1 & & 1 & & & 1 & & & & I & \\
\hline $\begin{array}{l}15-17 \\
\text { years }\end{array}$ & 2.0 & $(.97-4.05)$ & 1.3 & $(.6 I-2.76)$ & 1.4 & $(.62-3.09)$ & & 1.3 & $(.54-3.12)$ & & & 1.4 & $(.58-3.56)$ \\
\hline$<15$ years & 6.7 & (2.94-15.44) & 2.6 & $(1.01-6.76)$ & 2.7 & $(.92-7.66)$ & & 2.1 & $(.76-5.88)$ & & & 2.2 & $(.76-6.44)$ \\
\hline \multicolumn{14}{|l|}{$\begin{array}{l}\text { Learning \& } \\
\text { education }\end{array}$} \\
\hline \multicolumn{14}{|l|}{$\begin{array}{l}\text { Learning } \\
\text { difficulties at } \\
\text { school }\end{array}$} \\
\hline No & 1 & & 1 & & 1 & & & & & 1 & & 1 & \\
\hline Yes & 3.8 & $(1.76-8.03)$ & 2.9 & $(1.33-6.30)$ & 4.3 & $(1.83-9.95)$ & & & & 1.2 & $(.42-3.2 I)$ & 1.6 & $(.52-4.87)$ \\
\hline Missing & 8.4 & $(4.30-16.35)$ & 6.5 & $(3.34-12.60)$ & 7.0 & (3.67-13.22) & & & & * & & $*$ & \\
\hline \multicolumn{14}{|l|}{$\begin{array}{l}\text { Basic } \\
\text { education }\end{array}$} \\
\hline $\begin{array}{l}\text { High } \\
\text { school }\end{array}$ & 1 & & 1 & & 1 & & & & & I & & 1 & \\
\hline $\begin{array}{l}\text { Less than } \\
\text { high } \\
\text { school }\end{array}$ & 6.4 & $(3.64-11.29)$ & 5.4 & $(3.02-9.62)$ & 4.4 & $(2.39-7.99)$ & & & & 3.1 & $(1.60-6.14)$ & 1.8 & $(.93-3.65)$ \\
\hline $\begin{array}{l}\text { Log } \\
\text { likelihood } \\
\text { of the } \\
\text { model }\end{array}$ & & & & & & -332.564 & -319.966 & -297.473 & & -320.756 & & -283.803 & \\
\hline $\begin{array}{l}\text { Likelihood } \\
\text { ratio chi2 } \\
\text { (df) }\end{array}$ & & & & & & & $25.196(4)$ & $70.182(5)$ & & $23.616(2)$ & & $\begin{array}{l}97.522 \\
\text { (II) }\end{array}$ & \\
\hline$P$ value & & & & & & & $<.001$ & $<.001$ & & $<.001$ & & $<.001$ & \\
\hline
\end{tabular}

a Calculated using expansion weights

b Compared to Model I

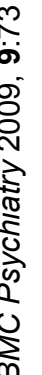

Dropped due to collinearity with missingness in Attention or behavior problems at school

the column labelled "Blocks" gives results for each variable adjusting for other variables from the same block.

作 adjusted for. Associations significant at $\mathrm{p}<.05$ or lower are shown in boldface.

$\mathrm{R}$, odds ratio; $\mathrm{AOR}$, adjusted odds ratio; $\mathrm{Cl}$, confidence interval 
ated daily smoking before age 15 had a strong association with SUD (AOR = 7.5). We also ran the analyses using the aggression score as a continuous variable, and no significant changes were seen in the results for other variables. The AOR associated with a 1 unit change in aggression in the final model was 1.1 (95\%CI: 1.00-1.14, $\mathrm{p}=.051$ ).

Although the AORs for many variables were nonsignificant in Models II-V, these additional domains of correlates clearly improved the statistical prediction of SUD over behavioral and affective factors only, as is evident from the statistically significantly higher maximum likelihood of these models compared to Model I (Table 4). These comparions take account of the number of additional variables.

\section{Discussion \\ Prevalence of alcohol and other substance use disorders}

Using population-based data and comprehensive diagnostic assessment based on structured clinical interview and medical case records, we found that approximately $14 \%$ of Finnish young adults had a lifetime SUD, and that an overwhelming majority of the cases were alcohol disorders. In general, the prevalences were higher in men than in women. The estimated lifetime prevalence of any SUD was fairly similar to recent estimates for the US from the National Comorbidity Survey Replication, which reported a lifetime prevalence of $16.7 \%$ of any SUD in the age group 18-29 years [2]. On the other hand, The National Epidemiologic Survey on Alcohol and Related Conditions, also from the US, reported substantially higher lifetime prevalences of both alcohol $(30.1 \%)$ and drug disorders $(14.2 \%)$ in this age group $[3,11]$ compared to the present results $(13.1 \%$ and $4.4 \%$, respectively). In Europe, Wittchen et al. reported a similar lifetime prevalence of any substance disorder of $17.7 \%$ among adolescents and young adults (aged 14-24) [48].

In addition to true differences between populations, discrepancies in prevalence estimates between studies arise due to use of different diagnostic methods. Notably, both structured clinical interview (SCID-I) and medical record data over the participants' lifetime were used in the diagnostic assessment in the present study. This method was chosen to improve the assessment of clinical significance of the symptoms of mental disorders, which has been deemed a potential problem in psychiatric epidemiological studies [49]. Similar diagnostic assessment methodology was used previously in an epidemiologic study of psychotic disorders in Finland [50].

Information on the lifetime prevalence of alcohol and other substance use disorders among young adults in Finland has not been previously available. Pirkola et al. reported the lifetime prevalence of alcohol dependence of
$7.9 \%$ in the Health 2000 adult sample (aged 30 years and over) [51], whereas in the present sample of young adults the lifetime prevalence of alcohol dependence was 5.6\%. In an urban sample of 20-24-year-old Finns, Aalto-Setälä et al. estimated one-month prevalence of any SUD to be $6.2 \%$, but the sample only contained cases of alcohol and cannabis disorders [52]. The estimated prevalences of alcohol and other substance use disorders in young adults in the present study fit well with the known profile of substance use in the Nordic countries, characterized by a high level of drinking to intoxication and a fairly low level of use of substances other than alcohol [53-56]. For example, in our study, $75 \%$ of young adults reported having been drunk within 12 months, while only $8 \%$ reported lifetime use of cannabis for more than five times.

\section{Correlates of SUDs}

Unadjusted associations

Our findings replicated previous results of disinhibitory and affective traits as correlates of SUD $[7,8,20]$. The association between parental alcohol problems and SUD in the offspring was also expected due to the strong familial pattern of substance use problems $[21,57]$. The effect of parental education is less well studied, but our results point to the possibility of elevated risk for SUD related to low parental education. The finding that early initiation of drinking to intoxication was strongly associated with SUD was anticipated [24], but somewhat surprising was the even stronger association between early onset of smoking and SUD, albeit evidence for the effect of early onset smoking on alcohol and drug disorders has been reported previously $[26,28,58]$. The observed association between own low education and SUD was not surprising on the grounds of previous studies $[2,3,11]$, but the predictive value of learning difficulties has not been widely studied.

Majority of the studies looking into risk factors for SUDs have been conducted in Anglo-Saxon societies (e.g. refs. $[7,8,29,32,34,58,59])$. However, the availability of substances and the prevailing general culture of substance use potentially influence the associations between risk factors and SUDs. Thus, it is of importance that the correlates studied here, selected on the basis of previous research, were associated with SUD also in the present sample of young adults from Finland. This finding suggests that the importance of cultural factors notwithstanding, these factors are related to SUDs despite varying cultures of alcohol and other substance use. Further, in an earlier study on this sample, we found several of the correlates reported here to be related to poorer cognitive functioning observed in young adults with SUDs [39].

\section{Adjusted associations}

Although the measures of attention or behavior problems at school, trait aggression and anxiousness were conceptu- 
alized as belonging to the same class of phenomena, our results suggest that they associate with SUD partly independently of each other. This result indicates that in addition to disinhibitory traits, also trait anxiety is strongly associated with elevated risk for SUD. Whether the relationship between anxiety and SUD is causal or reflects shared underlying vulnerability, is currently unknown [20]. It should also be noted that our measure of trait aggression did not assess actual aggressive behavior, but should be regarded as an index of a disposition to experience aggressive feelings.

In their longitudinal study from New Zealand, Fergusson et al. assessed the effect of childhood and adolescence conduct and attentional problems on later substance use, abuse and dependence, controlling for various social, family and individual covariates [8]. They found that conduct problems in adolescence were significantly related to use, abuse and dependence of various substances even when the wide array of covariates was included in the model. Another recent longitudinal study also found various self-reported problem behaviors in adolescence to predict SUDs in early adulthood, controlling for maternal education and alcohol use among other factors [60]. Our cross-sectional results, suggesting that the association between behavioral and affective factors and lifetime SUD diagnosis is largely independent of factors related to parents, early initiation of tobacco and alcohol use, and education and learning, are well in line with the findings of these studies. Taken together, these results emphasize the importance of disinhibitory and affective factors associated with SUDs.

Our results suggest that the associations of parental alcohol problems and low basic education with SUD in the offspring are at least partly mediated by the offspring's attention or behavior problems at school, aggression and anxiousness. This interpretation is based on results from Model II, where the previously significant associations between parental factors and SUD were rendered nonsignificant by behavioral and affective factors in the model. This finding is compatible with previous studies reporting that the effect of parental substance use problems on SUDs in the offspring is partly explained by the offspring's disinhibitory traits [59]. Interestingly, a twin study utilizing a children-of-twins design found evidence for the hypothesis that paternal SUD and disinhibitory traits in the offspring have a partly shared genetic background [61].

Smoking increased the odds for SUD irrespective of the age at initiation, but the risk related to daily smoking initiation before age 15 was remarkably elevated. It is well known that cigarette smoking often predates alcohol and drug use, but the meaning of this observation is debated.
Our results extend previous findings that age at smoking initiation is a risk factor for SUD independent of family history of alcoholism $[26,58]$ by providing evidence that the association between early smoking initiation and SUD is not accounted for by behavioral and affective factors, parental factors, age at initiation of alcohol use, learning difficulties or lower education. In contrast, the association between early initiation of drinking to intoxication and SUD may be accounted for by smoking and gender, as this association was non-significant when adjusted for these factors.

The relationship between behavioral and affective factors and educational factors was of special interest in the present study. As attention or behavior problems at school are bound to be associated with the level of achieved education, it is noteworthy that our results suggested that the association between low educational level and SUD is only partly accounted for by behavioral and affective factors. Epidemiological surveys have frequently identified low education as a risk factor for SUD $[2,3,11]$, but these studies rarely include other than sociodemographic factors. Our results suggest a relationship between lower education and SUD even when behavioral and affective factors and learning difficulties are taken into account. The temporal nature of this relationship between SUD and education cannot be determined in the present study, but in more than half of the cases the age at first abuse or dependence diagnosis was younger than 19, suggesting that in these cases problematic substance use predated or took place simultaneously with the processes leading to lower educational level. In contrast, learning difficulties did not have an association with SUD independently of behavioral and affective factors. We thus failed to replicate a previous finding that learning difficulties would increase the risk for SUD independently of behavior problems [62]. However, in the Beitchman et al. study learning difficulties were objectively tested for, whereas in the present study they were retrospectively selfreported.

\section{Limitations}

The present findings should be considered in conjunction with several limitations. First, as the data are cross-sectional, no conclusions about causality between the measures can be made. Secondly, the variables used in this study were self-reported, and the possibility that those reporting more problematic substance use would be prone to report higher (or lower) levels of other negative factors cannot be excluded. However, it should be noted that several measures of the present study come from a general health survey, conducted at least two years before the psychiatric assessment and not profiled as focusing specifically on SUDs, which should reduce bias in reporting. Third, the assessment of the four domains of corre- 
lates of SUD can in no case be considered comprehensive. For example, the single item used to assess anxiousness arguably provides a very limited assessment of affective factors. A fourth limitation has to do with missing data in the Health 2000 variables. In some logistic regression models missingness indicated elevated risk for SUD, reflecting the difficulty of studying individuals with serious substance use problems. However, when all the correlates were assessed, missingness ceased to have a significant effect. In any case, the effect of missing data should be taken into account when assessing the results related to these variables. A further limitation is that it was not feasible to study men and women separately. Significant interactions between gender and two risk factors were observed, but because of the small number of women with SUD in the sample, these interaction terms were not included in the multiple logistic regression models. In addition, due to the small number of other than alcohol disorders, substance specific correlates could not be assessed. A final limitation concerns attrition. As explained in the Methods, due to the two-phase study design, there were non-respondents in both of the study phases. However, non-response was not related to selfreported mental health or alcohol use problems [38]. To statistically correct for non-response, post-stratification and expansion weights were used both in estimating the prevalences and in the logistic regression models.

\section{Conclusion}

Prevalence of lifetime any substance use disorder is approximately $14 \%$, and alcohol disorder approximately $13 \%$ among Finnish young adult population, illicit substance use disorder without an alcohol disorder thus being very rare. Behavioral and affective factors, parental factors, early initiation of substance use, and learning difficulties and lower education were all found to be associated with alcohol and other substance use disorders. The association with behavioral and affective factors was only partly accounted for by other correlates. In contrast, only daily smoking and lower education associated with SUD when behavioral and affective factors were taken into account. Associations between many risk factors and SUD may be reflections of behavioral and afffective factors.

\section{Competing interests}

The authors declare that they have no competing interests.

\section{Authors' contributions}

JS, AT-H, JP, SIS, TA-S, HA, SK and JL contributed to the conception and design of the MEAF study. SK and JS also contributed to the conception and design of the baseline survey (Health 2000). JS, AT-H, JP, SIS and TA-S contributed to acquisition of data. AL planned and undertook the statistical analyses, and wrote the first draft of the manuscript. JS, AT-H, SK, TK and JK contributed to the design and discussion of the analyses. All authors participated in revising the manuscript for intellectual content by providing critical comments and have approved the final manuscript.

\section{Acknowledgements}

This study was supported by grants from the Academy of Finland (Dr. Suvisaari, grant 210714; Dr. Tuulio-Henriksson, grant II7I59; Dr. Kaprio, grant I 18555), the Academy of Finland Centre of Excellence in Complex Disease Genetics (Dr. Kaprio), the Yrjö Jahnsson Foundation (Dr. Suvisaari, Dr. Aalto-Setälä), and the Jalmari and Rauha Ahokas Foundation (Dr. AaltoSetälä). The funding sources had no involvement in study design; in the collection, analysis and interpretation of data; in the writing of the report; or in the decision to submit the paper for publication. We thank Merja Blom, Margit Keinänen-Guillaume, Helena Kurru, Maija Lindgren, MPsych, Anu Castaneda, MPsych, Taina Laajasalo, PhD, Marko Manninen, MPsych, Tuula Mononen and Sebastian Therman, MPsych, for skillfully conducted interviews, and Tuula Koski, Kirsi Niinistö, and Satu Viertiö, MSc, for administrative work. We also thank Arpo Aromaa, MD, PhD, and all the other collaborators in the Health 2000 study group, as well as all participants.

\section{References}

I. Jacobi F, Wittchen HU, Holting C, Hofler M, Pfister H, Muller N, Lieb $\mathrm{R}$ : Prevalence, co-morbidity and correlates of mental disorders in the general population: results from the German Health Interview and Examination Survey (GHS). Psychol Med 2004, 34:597-6II.

2. Kessler RC, Berglund P, Demler O, Jin R, Walters EE: Lifetime prevalence and age-of-onset distributions' of DSM-IV disorders in the national comorbidity survey replication. Arch Gen Psychiatry 2005, 62:593-602.

3. Hasin DS, Stinson FS, Ogburn E, Grant BF: Prevalence, correlates, disability, and comorbidity of DSM-IV alcohol abuse and dependence in the United States - Results from the National Epidemiologic Survey on Alcohol and Related Conditions. Arch Gen Psychiatry 2007, 64:830-842.

4. Ohlmeier MD, Peters K, Wildt BTT, Zedler M, Ziegenbein M, Wiese $B$, Emrich HM, Schneider U: Comorbidity of alcohol and substance dependence with attention-deficit/hyperactivity disorder (ADHD). Alcohol 2008, 43:300-304.

5. Rose RJ, Dick DM, Viken RJ, Pulkkinen L, Kaprio J: Genetic and environmental effects on conduct disorder and alcohol dependence symptoms and their covariation at age 14. Alcohol Clin Exp Res 2004, 28: 154 I- I 548.

6. Rubio G, Jimenez M, Rodriguez-Jimenez R, Martinez I, Avila C, Ferre $\mathrm{F}$, Jimenez-Arriero MA, Ponce G, Palomo T: The role of behavioral impulsivity in the development of alcohol dependence: $A$ 4year follow-up study. Alcohol Clin Exp Res 2008, 32:168I-I687.

7. Elkins IJ, McGue M, lacono WG: Prospective effects of attentiondeficit/hyperactivity disorder, conduct disorder, and sex on adolescent substance use and abuse. Arch Gen Psychiatry 2007, 64: I| $45-1 \mid 52$.

8. Fergusson DM, Horwood LJ, Ridder EM: Conduct and attentional problems in childhood and adolescence and later substance use, abuse and dependence: Results of a 25-year longitudinal study. Drug Alcohol Depend 2007, 88:SI4-S26.

9. Masse LC, Tremblay RE: Behavior of boys in kindergarten and the onset of substance use during adolescence. Arch Gen Psychiatry 1997, 54:62-68.

10. Caspi A, Moffitt TE, Newman DL, Silva PA: Behavioral observations at age 3 years predict adult psychiatric disorders - Longitudinal evidence from a birth cohort. Arch Gen Psychiatry 1996, 53:1033-1039.

II. Compton WM, Thomas YF, Stinson FS, Grant BF: Prevalence, correlates, disability, and comorbidity of DSM-IV drug abuse and dependence in the United States - Results from the National Epidemiologic Survey on Alcohol and Related Conditions. Arch Gen Psychiatry 2007, 64:566-576.

12. Kessler RC, Chiu WT, Demler O, Walters EE: Prevalence, severity, and comorbidity of I2-month DSM-IV disorders in the 
National Comorbidity Survey Replication. Arch Gen Psychiatry 2005, 62:617-627.

13. van Beijsterveldt CEM, Bartels M, Hudziak JJ, Boomsma DI: Causes of stability of aggression from early childhood to adolescence: A longitudinal genetic analysis in Dutch twins. Behav Genet 2003, 33:59I-605.

14. Vierikko E, Pulkkinen L, Kaprio J, Viken R, Rose RJ: Sex differences in genetic and environmental effects on aggression. Aggress Behav 2003, 29:55-68

15. Pulkkinen L, Pitkänen T: Continuities in Aggressive-Behavior from Childhood to Adulthood. Aggress Behav 1993, 19:249-263.

16. Moss HB, Kirisci L: Aggressivity in Adolescent Alcohol Abusers - Relationship with Conduct Disorder. Alcohol Clin Exp Res 1995, 1 9:642-646.

17. Schuckit MA, Hesselbrock V: Alcohol Dependence and Anxiety Disorders - What Is the Relationship. Am J Psychiatry 1994, I5 I: I723-I734.

18. Grant BF, Stinson FS, Dawson DA, Chou SP, Dufour MC, Compton W, Pickering RP, Kaplan K: Prevalence and co-occurrence of substance use disorders and independent mood and anxiety disorders - Results from the national epidemiologic survey on alcohol and related conditions. Arch Gen Psychiatry 2004, 6I:807-8I6.

19. Pirkola SP, Isometsä E, Suvisaari J, Aro H, Joukamaa M, Poikolainen K, Koskinen S, Aromaa A, Lönnqvist JK: DSM-IV mood-, anxietyand alcohol use disorders and their comorbidity in the Finnish general population - Results from the Health 2000 Study. Soc Psychiatry Psychiatr Epidemiol 2005, 40: I- I0.

20. Zimmermann P, Wittchen HU, Hofler M, Pfister H, Kessler RC, Lieb $\mathrm{R}$ : Primary anxiety disorders and the development of subsequent alcohol use disorders: a 4-year community study of adolescents and young adults. Psychol Med 2003, 33:I2II-I 222

21. Merikangas KR, Stolar M, Stevens DE, Goulet J, Preisig MA, Fenton B, Zhang HP, O'Malley SS, Rounsaville BJ: Familial transmission of substance use disorders. Arch Gen Psychiatry 1998, 55:973-979.

22. Prescott CA, Kendler KS: Genetic and environmental contributions to alcohol abuse and dependence in a population-based sample of male twins. Am J Psychiatry 1999, 156:34-40.

23. Lieb R, Merikangas KR, Hofler M, Pfister H, Isensee B, Wittchen HU: Parental alcohol use disorders and alcohol use and disorders in offspring: a community study. Psychol Med 2002, 32:63-78.

24. DeWit DJ, Adlaf EM, Offord DR, Ogborne AC: Age at first alcohol use: A risk factor for the development of alcohol disorders. Am J Psychiatry 2000, I 57:745-750.

25. Prescott CA, Kendler KS: Age at first drink and risk for alcoholism: A noncausal association. Alcohol Clin Exp Res 1999 23: $101-107$.

26. Hanna EZ, Grant BF: Parallels to early onset alcohol use in the relationship of early onset smoking with drug use and DSMIV drug and depressive disorders: Findings from the national longitudinal epidemiologic survey. Alcohol Clin Exp Res 1999, 23:513-522.

27. Morgen CS, Bove KB, Larsen KS, Kjaer SK, Gronbaek M: Association between smoking and the risk of heavy drinking among young women: A prospective study. Alcohol Alcohol 2008, 43:37I-375.

28. Vega WA, Gil AG: Revisiting drug progression: long-range effects of early tobacco use. Addiction 2005, 100:1358-1369.

29. Crum RM: Educational achievement and early school behavior as predictors of alcohol-use disorders: 35-year follow-up of the Woodlawn Study. I Stud Alcohol 2006, 67:75-85.

30. Kestilä L, Martelin T, Rahkonen O, Joutsenniemi K, Pirkola S, Poikolainen K, Koskinen S: Childhood and current determinants of heavy drinking in early adulthood. Alcohol Alcohol 2008 , 43:460-469.

31. Capone C, Wood MD: Density of familial alcoholism and its effects on alcohol use and problems in college students. Alcohol Clin Exp Res 2008, 32: I45I-I458.

32. Elkins IJ, McGue M, Malone S, lacono WG: The effect of parental alcohol and drug disorders on adolescent personality. $\mathrm{Am}$ Psychiatry 2004, 161:670-676.

33. Hussong AM, Wirth RJ, Edwards MC, Curran PJ, Chassin LA, Zucker RA: Externalizing symptoms among children of alcoholic parents: Entry points for an antisocial pathway to alcoholism. J Abnorm Psychol 2007, I I 6:529-542.
34. King SM, lacono WG, McGue M: Childhood externalizing and internalizing psychopathology in the prediction of early substance use. Addiction 2004, 99: I548-I559.

35. Jackson KM, Sher KJ, Schulenberg JE: Conjoint developmental trajectories of young adult substance use. Alcohol Clin $\operatorname{Exp}$ Res 2008, 32:723-737.

36. Aromaa A, Koskinen S, (Eds): Health and functional capacity in Finland. Baseline results of the Health 2000 health examination survey Volume BI2. Helsinki, Finland: Publications of the National Public Health Institute; 2004

37. Pirkola S, Isometsä E, Aro H, Kestilä L, Hämäläinen J, Veijola J, Kiviruusu O, Lönnqvist ]: Childhood adversities as risk factors for adult mental disorders. Soc Psychiatry Psychiatr Epidemiol 2005, 40:769-777.

38. Suvisaari J, Aalto-Setälä T, Tuulio-Henriksson A, Härkänen T, Saarn SI, Perälä J, Schreck M, Castaneda A, Hintikka J, Kestilä L, et al.: Mental disorders in young adulthood. Psychol Med 2009, 39:287-299.

39. Latvala A, Castaneda AE, Perälä J, Saarni SI, Aalto-Setälä T, Lönnqvist J, Kaprio J, Suvisaari J, Tuulio-Henriksson A: Cognitive functioning in substance abuse and dependence: $A$ population-based study of young adults. Addiction 2009, 104:1558-1568.

40. Mayfield D, McLeod G, Hall P: The CAGE questionnaire: validation of a new alcoholism screening instrument. Am J Psychiatry 1974, I3 I:I| |2|-| I23.

4I. First MB, Spitzer RL, Gibbon M, Williams JBW: Structured Clinical Interview for DSM-IV-TR Axis I Disorders - Patient Edition (SCID IIP, 2/200I Revision) New York: Biometrics Research, New York State Psychiatric Institute; 200I.

42. Buss AH, Perry M: The Aggression Questionnaire. J Pers Soc Psychol 1992, 63:452-459.

43. Fröjd S, Kaltiala-Heino R, Rimpelä M: The association of parental monitoring and family structure with diverse maladjustment outcomes in middle adolescent boys and girls. Nord J Psychiatry 2007, 6I:296-303.

44. Dunn G, Pickles A, Tansella M, Vazquez-Barquero JL: Two-phase epidemiological surveys in psychiatric research. Br J Psychiatry 1999, 174:95-100.

45. Pickles A, Dunn G, Vazquez-Barquero JL: Screening for stratification in two-phase ('two-stage') epidemiological surveys. Stat Methods Med Res 1995, 4:73-89.

46. StataCorp: Stata Statistical Software: Release 9 College Station, TX: StataCorp LP; 2005

47. Schafer JL, Graham JW: Missing data: Our view of the state of the art. Psychol Methods 2002, 7:147-177.

48. Wittchen HU, Nelson CB, Lachner G: Prevalence of mental disorders and psychosocial impairments in adolescents and young adults. Psychol Med 1998, 28:109-126.

49. Regier DA, Kaelber CT, Rae DS, Farmer ME, Knauper B, Kessler RC Norquist GS: Limitations of diagnostic criteria and assessment instruments for mental disorders - Implications for research and policy. Arch Gen Psychiatry 1998, 55:109-II5.

50. Perälä J, Suvisaari J, Saarni SI, Kuoppasalmi K, Isometsä E, Pirkola S, Partonen T, Tuulio-Henriksson A, Hintikka J, Kieseppa T, et al.: Lifetime prevalence of psychotic and bipolar I disorders in a general population. Arch Gen Psychiatry 2007, 64:19-28.

5I. Pirkola SP, Poikolainen K, Lönnqvist JK: Currently active and remitted alcohol dependence in a nationwide adult general population-results from the finnish health $\mathbf{2 0 0 0}$ study. Alcohol Alcohol 2006, 41:3I5-320.

52. Aalto-Setälä T, Marttunen M, Tuulio-Henriksson A, Poikolainen K, Lönnqvist J: One-month prevalence of depression and other DSM-IV disorders among young adults. Psychol Med 200I, 31:79I-80I.

53. EMCDDA: The State of the Drugs Problem in Europe European Monitoring Centre for Drugs and Drug Addiction; 2008.

54. Halme JT, Seppä K, Alho H, Pirkola S, Poikolainen K, Lönnqvist J, Aalto M: Hazardous drinking: Prevalence and associations in the Finnish general population. Alcohol Clin Exp Res 2008, 32:1615-1622.

55. Kringlen E, Torgersen S, Cramer V: A Norwegian psychiatric epidemiological study. Am J Psychiatry 200I, I58:1091-1098.

56. WHO: Global Status Report on Alcohol 2004 Geneva: World Health Organization; 2004

57. Dick DM, Bierut LJ: The Genetics of Alcohol Dependence. Curr Psychiatry Rep 2006, 8: I5I-157. 
58. Grant BF: Age at smoking onset and its association with alcohol consumption and DSM-IV alcohol abuse and dependence: Results from the national longitudinal alcohol epidemiologic survey. J Subst Abuse 1998, 10:59-73.

59. Chassin L, Flora DB, King KM: Trajectories of alcohol and drug use and dependence from adolescence to adulthood: The effects of familial alcoholism and personality. J Abnorm Psychol 2004, I I 3:483-498.

60. Hayatbakhsh MR, Najman JM, Jamrozik K, Al Mamun A, Bor W, Alati R: Adolescent problem behaviours predicting DSM-IV diagnoses of multiple substance use disorder. Soc Psychiatry Psychiatr Epidemiol 2008, 43:356-363.

61. Haber JR, Jacob T, Heath AC: Paternal alcoholism and offspring conduct disorder: Evidence for the 'common genes' hypothesis. Twin Res Hum Genet 2005, 8: I20-I 3 I.

62. Beitchman JH, Wilson B, Douglas L, Young A, Adlaf E: Substance use disorders in young adults with and without LD: Predictive and concurrent relationships. J Learn Disabil 200I, 34:317-332.

\section{Pre-publication history}

The pre-publication history for this paper can be accessed here:

http://www.biomedcentral.com/1471-244X/9/73/pre pub

Publish with Bio Med Central and every scientist can read your work free of charge

"BioMed Central will be the most significant development for disseminating the results of biomedical research in our lifetime. "

Sir Paul Nurse, Cancer Research UK

Your research papers will be:

- available free of charge to the entire biomedical community

- peer reviewed and published immediately upon acceptance

- cited in PubMed and archived on PubMed Central

- yours - you keep the copyright 